\title{
EVALUATION OF NUCLEATE BOILING HEAT FLUX PREDICTIONS AT VARYING LEVELS OF SUBCOOLING AND ACCELERATION
}

\author{
R. L. JUDD \\ Department of Mechanical Engineering, McMaster University, Hamilton, Ontario, Canada \\ and \\ H. MERTE, JR. \\ Department of Mechanical Engineering, University of Michigan, Ann Arbor, Michigan, U.S.A.
}

(Received 25 May 1971 and in revised form 6 October 1971)

\begin{abstract}
The heat flux predictions of six different models proposed to explain the nucleate boiling phenomenon are compared with the corresponding heat flux measurements at the same levels of subcooling and acceleration. It is shown that none of these models can adequately predict nucleate boiling heat flux for other than saturated boiling conditions at standard gravity and that all of the models agree in predicting decreasing values of heat flux as subcooling and acceleration increase. This observation suggests the omission of some additional mechanism which is inoperative under saturated boiling conditions at standard gravity but very sensitive to the level of subcooling and acceleration. An empirical procedure is presented for correlating the results used in making the comparisons.
\end{abstract}

\section{NOMENCLATURE}

$a / g, \quad$ dimensionless acceleration;

A, area;

C, specific heat;

$D$, diameter;

$f$, frequency;

$F, \quad$ instantaneous area fraction covered by bubbles;

$\mathscr{F}, \quad$ time average area fraction covered by bubbles;

$g$, gravitational acceleration;

$g_{c}$, mass force conversion constant;

$h_{f g}, \quad$ heat of vapourization;

$k, \quad$ thermal conductivity;

$n / A, \quad$ population density:

$N / A, \quad$ active site density;

$Q / A$, heat flux;

$t, \quad$ time;

$T, \quad$ temperature;

$U$, bubble velocity.

\section{Greek symbols}

$\alpha, \quad$ thermal diffusivity;

$\beta, \quad$ volumetric coefficient of expansion;

$\gamma$, parameter relating heat transfer to strength of stagnation flow;

$\delta, \quad$ liquid layer thickness;

$\varepsilon, \quad$ vapour fraction;

$v, \quad$ kinematic viscosity;

$\xi, \quad$ thermal boundary layer thickness;

$\rho, \quad$ density;

$\sigma, \quad$ surface tension;

$\tau, \quad$ elapsed time;

$\psi$, function relating heat transfer to manner in which vapour liquid interface recedes.

Dimensionless parameters

$\mathrm{Nu}$, bubble Nusselt number.

$P r, \quad$ Prandtl number;

$R e$, bubble Reynolds number. 


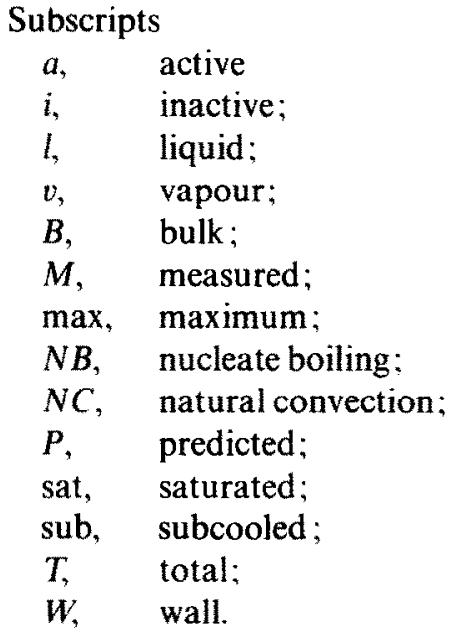

\section{INTRODUCTION}

THE AVAILABILITY of simultaneous measurements of the dependent variables heater surface temperature, nucleation site density, bubble frequency and maximum bubble size as a function of heat flux, subcooling and acceleration for Freon 113 boiling on a horizontal surface affords an opportunity for testing various models for boiling heat transfer which exist in the literature. The basic measurements have been presented in [1], some of which will be repeated here for the sake of completeness. The models listed below and represented schematically in Fig. 1, will be tested by using the measurements to predict a heat flux which will be compared with the measured value.

Latent Heat Transport Model

Vapour Liquid Exchange Model

Enthalpy Transport Model

Source Flow Model

Wake Flow Model

Enhanced Natural Convection Model

The supposed operation of these models as presented by their proponents will be described later as each model is tested with the measurements of the present investigation. The paper will be concluded with the presentation of an empirical correlation of the experimental results.

\section{EXPERIMENTAL APPARATUS}

\section{Centrifuge}

A centrifuge capable of subjecting a $45.3 \mathrm{~kg}$ mass test package to accelerations from $a / g=1$ to $a / g=100$ was adapted for the present investigation. The test package was mounted at the end of a horizontal rotating crossarm on a pivot such that the heat transfer surface within was always oriented perpendicular to the vectoral sum of the centrifugal and gravitational

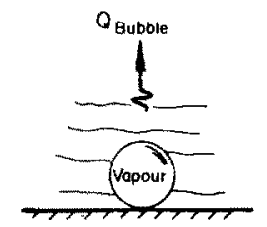

Lotent heat transport model

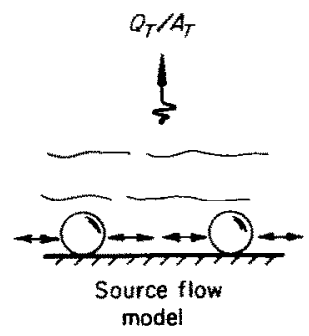

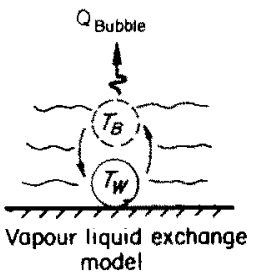

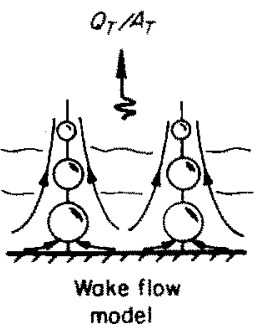

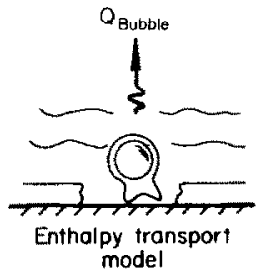

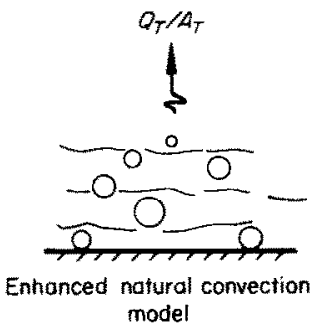

FIG. 1, Boiling heat transfer models. 
acceleration vectors. Continuous photography from the rotating test package to an external stationary camera was made possible by a system of lenses and mirrors in the hollow shaft and on the crossarm. Provision was made for the communication of cooling water, thermocouples, electric power, and other instrument signals to the rotating system. Details of the complete system are presented in [2].

\section{Surface-fluid combination}

A commercially prepared transparent oxide coated glass slide $50 \mathrm{~mm}$ long by $33 \mathrm{~mm}$ wide by $3.2 \mathrm{~mm}$ thick served as the heat transfer surface. The oxide coating contacted the test fluid, Freon 113 (trichlorotrifluoroethane), chosen because of its compatibility with the oxide coating, its nonhazardous characteristics and its near room temperature boiling point. Heat was generated by passing d.c. current through the oxide coating to produce nucleate boiling. Since an oxide coated glass surface might be expected to give results different from the usual metallic boiling heat transfer surfaces encountered in industrial applications, a limited series of measurements of heat flux and heater surface temperature were made with a stainless steel foil replacing the oxide coating. At $a / y=1$, the two surfaces performed identically except that a "hysteresis" effect occurred with the metal surface that was not present with the glass surface. At higher acceleration levels, the behavior between the two was similar as subcooling was varied, except that the glass surface took on levels of temperature higher by about $2^{\circ} \mathrm{C}$. A single oxide coated "test specimen was used

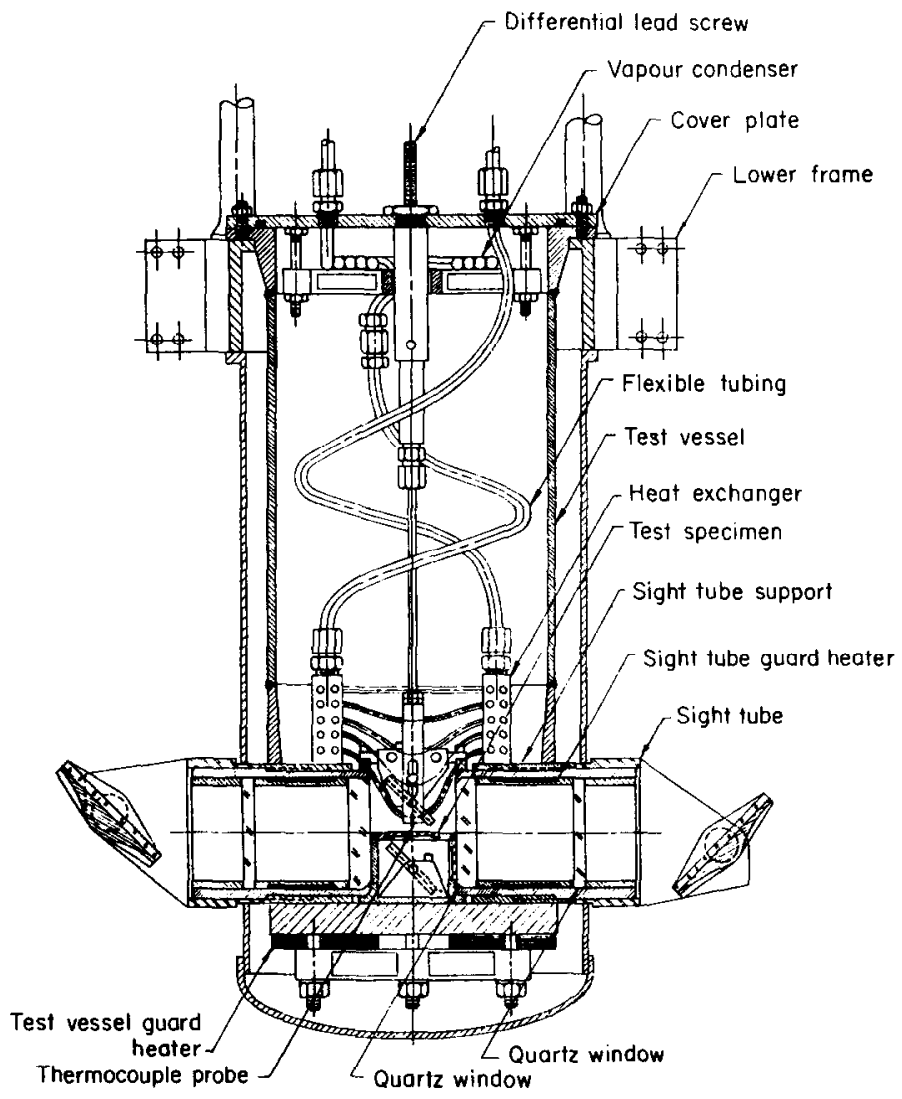

Fig. 2. Detail drawing of test package. 
throughout the study reported here, and therefore surface condition is not considered as a variable.

\section{Test package}

The various components of the test package are shown in Fig. 2. The transparent heat transfer surface permitted observation of the boiling phenomenon from beneath, normal to the heat transfer surface. The surface was mounted in a fixture, perpendicular to the centerline of the test package and at the centerline of the sight tubes, which encapsulated a small volume of air beneath to act as thermal insulation. The sight tube on the left introduced the light beam from an arc source to the liquid region above the heater surface, where a mirror deflected the beam downward. The image of the heater surface was then transmitted out the sight tube on the right to the camera. Guard heaters located in both sight tubes were independently adjusted to maintain the temperature of the air between the quartz windows at the temperature of the test fluid. A guard heater attached to the bottom of the test package was used in conjunction with the heat exchanger in the liquid to control the temperature of the test fluid. A vapour condenser was located at the top of package. The differential lead screw mounted on the centerline of the test package was driven by a remotely controlled electric motor, enabling a horizontal fine wire thermocouple probe $2.54 \times 10^{-2} \mathrm{~mm}$ dia. to be moved and located precisely in the vertical direction in order to measure the temperature distribution in the fluid adjacent to the heat transfer surface.

\section{Thermocouples}

Six fixed chromel-constantan thermocouples plus the traversing thermocouple probe were used to measure temperatures at various locations in the test packagc. The thermocouples were located in the liquid $25 \mathrm{~mm}$ above the heat transfer surface; in the liquid on the upper part of the movable thermocouple probe support; directly on the unheated underside of the test specimen; in the air space between the quartz windows in each of the sight tubes: and in the air space inside the test surface mounting fixture. The thermocouple signals were transmitted from the rotating system by means of a system of stationary circular trays containing mercury in which a molybdenum wire mounted on a plexiglas rotor was immersed. The rotating and stationary transition junctions between the molybdenum and chromel or constantan wires were all located in a single well stirred kerosene bath. A precision potentiometer measured the thermocouple outputs except for the movable thermocouple probe, which was recorded on a four channel recorder, along with the signals of the probe position sensing device, the probesurface contact indicator and the vapour space pressure transducer.

\section{Pressurization system}

The pressure at the heat transfer surface was maintained constant at $57.4 \mathrm{k} \mathrm{N} / \mathrm{m}^{2}$ gauge for all tests in order to maintain a constant saturation temperature at this surface. Varying the acceleration changed the hydrostatic pressure at the heat transfer surface, for which compensation was made by regulating the pressure of the helium atmosphere in the vapour space as monitored with a strain-gage type transducer.

\section{Optical system}

The beam of light used to backlight the nucleate boiling originated on the axis of rotation and was focused by a condensing lens and transmitted to the heat transfer surface approximately $1.2 \mathrm{~m}$ away by means of four first surface mirrors. The images of the bubbles wcre transmitted approximately $30 \mathrm{~m}$ at unity magnification through two long focal length lenses to the focal plane of the camera by means of five additional front surface mirrors. The camera used was a Beckman-Whitley Dynafax Model 326 framing camera.

Adequate exposure of the film for all combinations of heat flux, subcooling and acceleration was difficult to achieve because the bubbles 


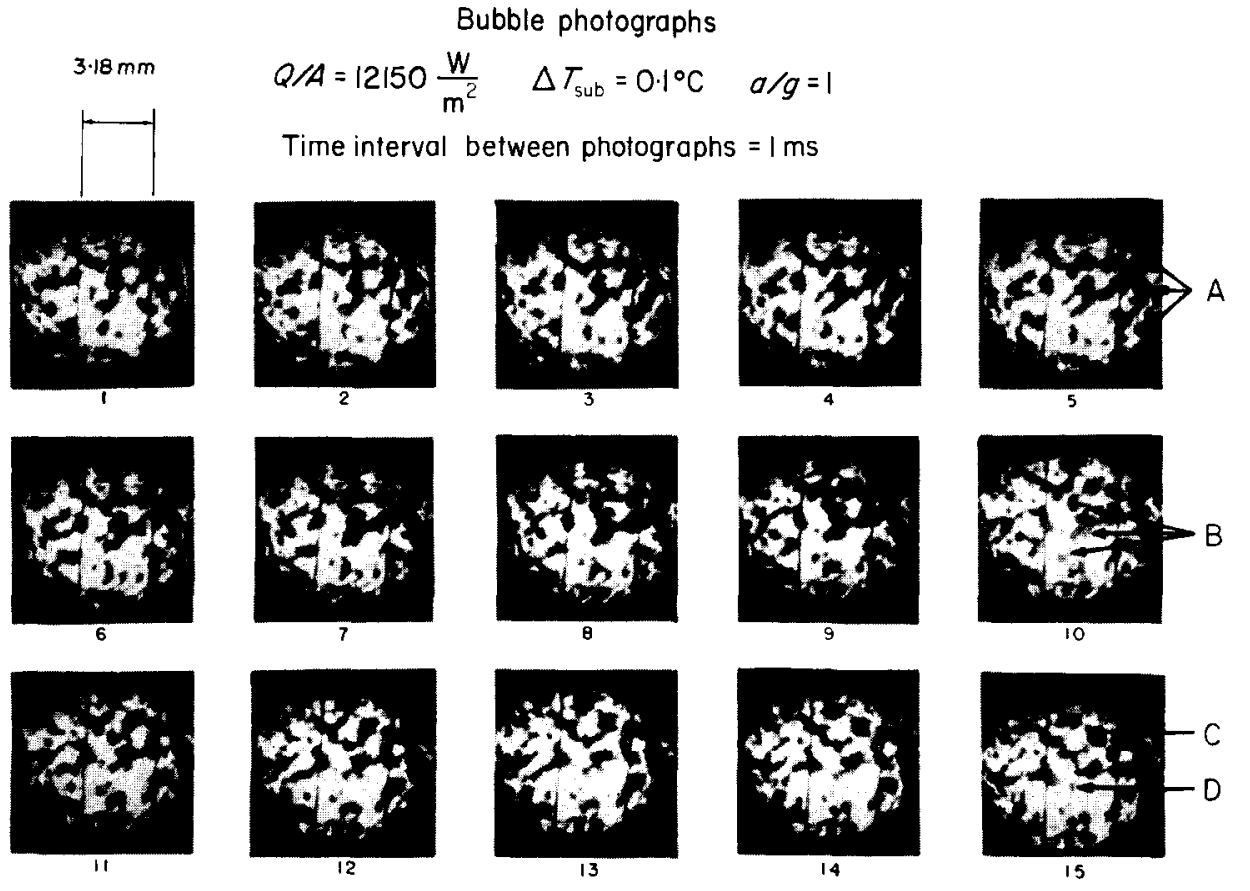

Fig. 3. A. Bubbles attached to surface. B. Bubbles detached from surface. C. Attached bubble. D. Detached bubble. 
dispersed much of the light incident upon the heat transfer surface under certain combinations of these three parameters. Three different high intensity arc lamps were used to backlight the boiling phenomenon at $a / g=1,10$ and 100 respectively, since different amounts of light were required for each of the different acceleration levels. Even then, the combination of high heat flux and low subcooling at $a / g=1$ could not be photographed because of the large amount of vapour generated.

\section{Test procedures}

Five levels of heat flux nominally $Q_{T} / A_{T}=$ $11500,21100,41600,82000$ and $129400 \mathrm{~W} / \mathrm{m}^{2}$, various levels of subcooling in the range $0^{\circ} \mathrm{C} \leqslant$ $\left(T_{\text {sat }}-T_{B}\right) \leqslant 30^{\circ} \mathrm{C}$ and three levels of acceleration $a / g=1,10$ and 100 were used in the present investigation. The heat flux was computed by dividing the total energy dissipation in the oxide film by the total surface area. The subcooling was computed by subtracting the bulk liquid temperature measured at a fixed location outside of the thermal boundary layer from the saturation temperature at the heat transfer surface. The temperature profile measurements in the liquid indicated that the bulk liquid temperature was relatively insensitive to displacement from the heat transfer surface at the location chosen so that the temperature measured was representative of the bulk liquid temperature: the saturation tempcrature at the heat transfer was maintained constant as explained earlier so that the subcooling computed in the manner described above was independent of the influence of acceleration.

At the beginning and conclusion of each series of tests in which subcooling and/or acceleration was varied at constant heat flux, a "reference test" was performed for saturated boiling at standard gravity in order to establish a test condition which could be used to evaluate the effects of changes in subcooling and acceleration. It was observed that inconsistencies in the data with variations in subcooling and acceleration were always related to the non-reproducibi- lity of the data with saturated liquid at $a / g=1$. On repeating tests under identical conditions, the heater surface superheat might differ by as much as $\pm 2^{\circ} \mathrm{C}$ from one day to the next. By pcrforming a "reference test" each day before and after each series of tests, comparison with a reference curve would indicate the extent of the deviation. A correction equal to this deviation was then applied to all heater surface temperature measurements in that series of tests. By this procedure, the results for various subcoolings and accelerations became reproducible.

When steady state test conditions had been attained, the outputs of the six fixed thermocouples and the other instrument systems were recorded. For those tests involving the measurement of the temperature distribution in the thermal boundary layer adjacent to the heater surface, a boundary layer traverse was performed immediately afterward. The thermocouple probe was driven downward until it touched the heat transfer surface, as indicated by a sudden increase in the voltage level of the probe. The probe was then driven upward and the angular position of the drive motor was noted at the instant that the probe broke contact with the heat transfer surface. Thereafter, the boundary layer traverse was interrupted for several seconds at intervals corresponding to one revolution of the drive motor $\left(1.12 \times 10^{-1}\right.$ $\mathrm{mm}$ ) in order to measure the temperature of the bulk liquid at a number of positions normal to the heat transfer surface. For those tests involving photography of the boiling phenomenon, two motion picture film strips were then exposed at both 1000 frames/s and 2000 frames/s. The film strips were processed immediately and checked for suitability before any parameters were varied.

\section{PHOTOGRAPHIC TEST RESULTS}

\section{Data analysis}

A sample of the photographs taken through the heating surface with nucleate boiling present is presented in Fig. 3. With the high magnifi- 
catıon and associated small depth of field, bubbles attached to the heater surface could be easily distinguished from others by their sharp outline.

Average population density and active site density were determined from photographic enlargements of sequences of frames on the film strips. In determining the active site density, each point at which bubbles were seen to be attached to the heat transfer surface was identified as a nucleation site. The active nucleation sites within the defined area in each enlargement were identified and transferred to a single enlargement, using established reference points. With the addition of each consecutive framc, previously observed sites often were duplicated, but a diminishing number of additional sites were added by each successive frame. The average population density was determined by averaging the number of bubbles attached to the heat transfer surface in each of the frames.

Frequency of bubble emission was determined from an analysis of the projected film strips. The growth of a single vapour bubble at each of ten different nucleation sites was followed

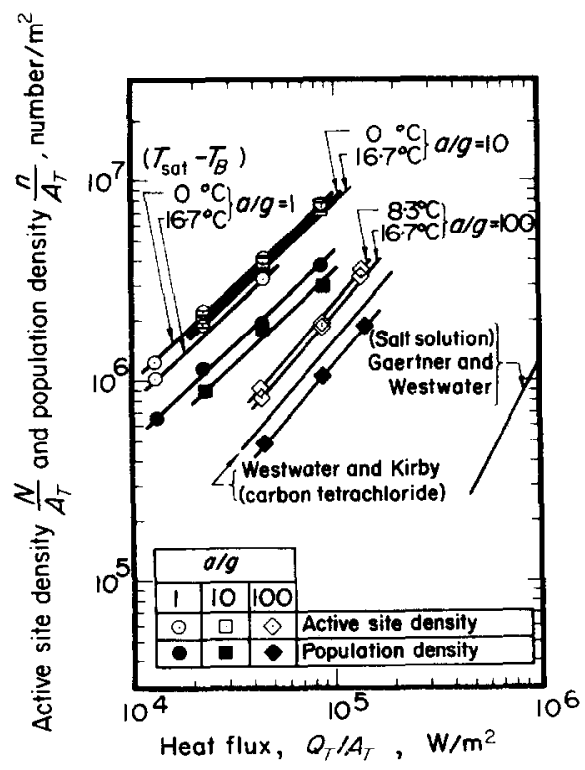

FIG. 4. Bubble density. frame by frame in order to determine the time elapsed from initiation to departure or collapse, designated as the "active" period. Frame by frame observation of the nucleation site was then continued to determine the time elapsed from departure or collapse to re-initiation, designed as the "inactive" period. The period of a bubble is the sum of the active and inactive periods, and the frequency of bubble emission is the reciprocal of this quantity.

Maximum bubble size was determined from the enlargements of the frame in which the bubble appeared to have grown to maximum size prior to the beginning of collapse or departure. The average of two perpendicular measurements of diameter was taken to be the maximum bubble size. It should be recognized that these views are obtained from beneath the heater surface, and the diameter may differ from that seen from the side.

Average population density and active site density

The influence of heat flux, subcooling and acceleration upon active site density and average population density is illustrated in Fig. 4. The active site density is the number of active nucleating sites per unit area present under given conditions. A bubble will not be present on an active site at a given instant of time during the waiting period, but will be present during the active period. The average population density is the average number of bubbles present on the surface per unit area at any given time. In Fig. 4 the average population density is approximately one half the active site density for the same levels of heat flux and acceleration. The active site density appears to be a linear function of heat flux at all levels of subcooling and acceleration. This is consistent with the saturated nucleate boiling results reported by Westwater [3] and Gaertner [4] at $a / g=1$, although considerably more active sites were observed in the present work. The results indicate the somewhat surprising fact that subcooling has relatively little influence on the active site density. It had been expected that increasing subcooling would 
cause the suppression of bubble nucleation. Increasing the acceleration level from $a / g=1$ to $a / g=10$ resulted only in a 10 per cent reduction in the active site density, whereas further increasing the acceleration level from $a / g=10$ to $a / g=100$ resulted in an 80 per cent reduction in the active site density. Both Graham [5] and Beckman [6] have reported similar acceleration induced changes in active site density.

\section{Frequency of bubble emission}

The data plotted in Fig. 5 depict the influence of heat flux, subcooling and acceleration upon the frequency of bubble emission. The

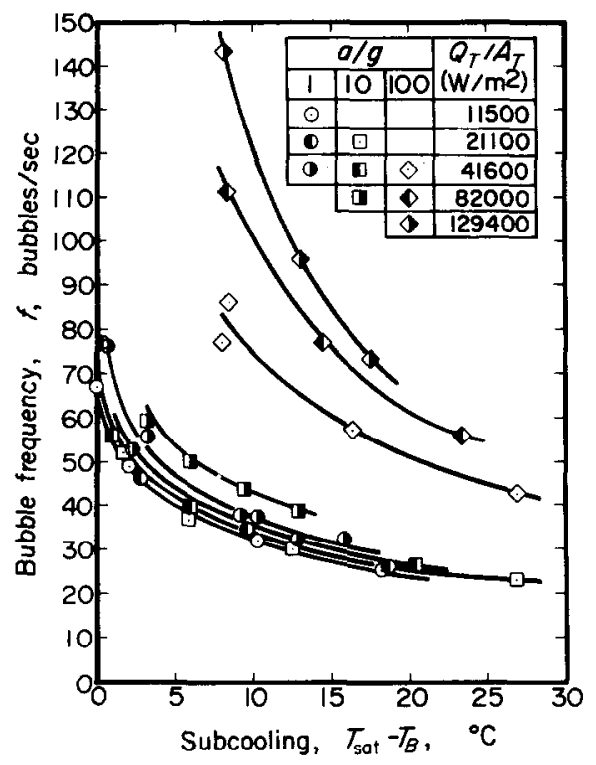

FIG. 5. Bubble frequency.

frequency of bubble emission varies directly with heat flux and indirectly with subcooling. Increasing the acceleration level from $a / g=1$ to $a / g=10$ resulted in little change in bubble frequency whereas increasing the acceleration level from $a / g=10$ to $a / g=100$ resulted in an increase in bubble frequency ranging from two to four fold, depending on the subcooling. Beckman [6] reported a tenfold increase in bubble frequency with an increase of acceleration from $a / g=1$ to $a / g=100$. In that case the minimum subcooling at $a / g=100$ was much smaller than the $8^{\circ} \mathrm{C}$ in Fig. 5. It is noted in Fig. 5 that a reduction in subcooling had a much greater influence on the bubble frequency at $a / g=100$ than at the lower levels at acceleration.

The heat flux behavior can be related to the fact that the heatcr surface tempcraturc and hence the temperature of the adjacent superheat layer increase with increasing heat flux. Hence, the vapour bubbles grew more rapidly and the process of vapour bubble departure or collapse commenced sooner since the vapour bubbles attained maximum size in a shorter interval of time.

The photographs show that both the growth period and the waiting period increase as subcooling is increased, at all acceleration levels. This means that the frequency must decrease, as observed, and the decrease is believed related to the decrease in surface temperature which accompanies increasing subcooling.

\section{Maximum bubble size}

Figure 6 shows the simultaneous influence

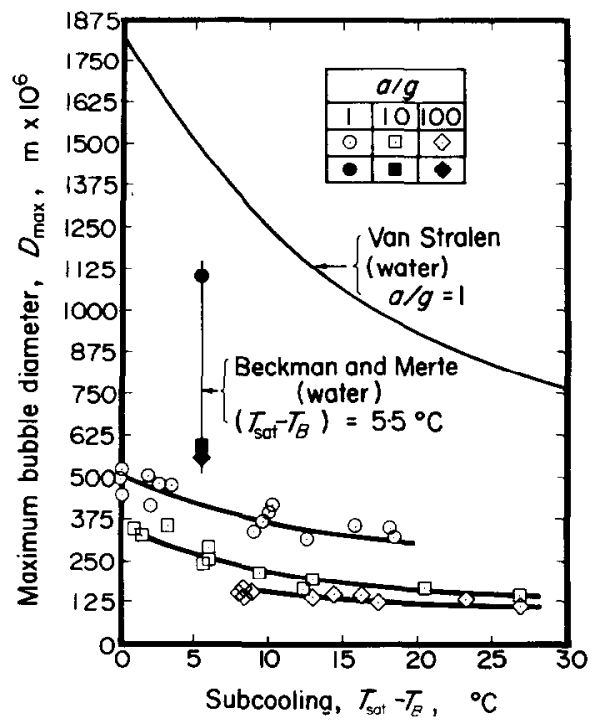

FIG. 6. Bubble size. 
of variations in acceleration and subcooling on the maximum size of the bubble while attached to the heat transfer surface as viewed from beneath. At all acceleration levels, increasing the subcooling resulted in a decrease in the maximum size, as has been observed by many workers at $a / g=1$. The results of Van Stralen [7] for water are included as typical. As acceleration was increased from $a / g=1$ to $a / g=10$, the dccrcasc in sizc was relativcly greater than the further decrease taking place when acceleration was increased from $a / g=10$ to $a / g=100$. A corresponding effect was observed by Beckman [6] with water at a fixed level of subcooling which is also included in Fig. 6.

The maximum bubble size appeared to be independent of heat flux in the ranges of heat flux and acceleration covered. This had also been reported by Beckman [6] for various accelerations and by Gaertner [8] at $a / g=1$.

\section{THERMOMETRIC TEST RESULTS}

\section{Surface temperature}

The influence of subcooling and acceleration upon the temperature of the heat transfer surface is indicated in Fig. 7, in which heater surface superheat has been plotted as a function of

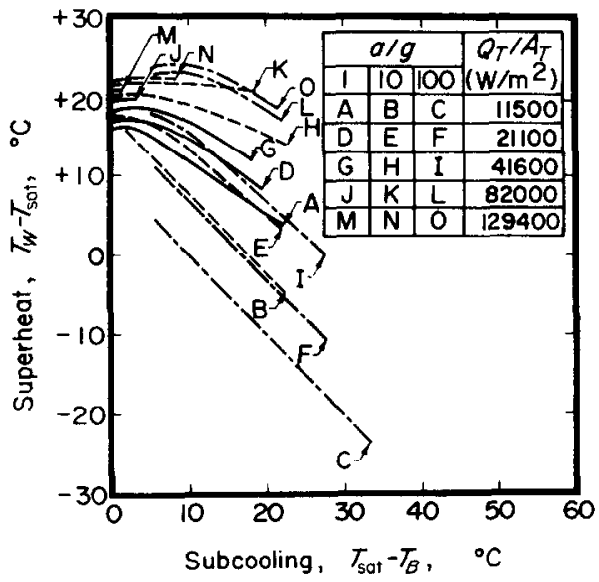

FIG. 7. Surface temperature. subcooling and acceleration for constant heat flux. Data points have been omitted from this plot for the sake of clarity. For a number of the curves, as subcooling is increased with constant heat flux and acceleration, the heater surface superheat first increases and then decreases. which is consistent with the observations of Merte [9]. It was found, in the photographic results presented above, that the frequency of bubble cmission and the maximum bubblc size decrease markedly with increasing subcooling, and it is reasonable to conclude that the heat transfer ascribed to each active site is thereby diminished. Thus, nucleate boiling becomes progressively less able to transfer the heat load as subcooling increases, requiring an increase in the surface temperature until subcooling increases sufficiently to enhance the natural convection mechanism to the point where the surface temperature decreases thereafter. Heat transfer by natural convection is dependent upon the surface-liquid temperature difference $\left(T_{W}-T_{B}\right)$, which assumes approximately a constant value for constant heat flux and acceleration, so that as subcooling $\left(T_{\text {sat }}-T_{B}\right)$ increases, superheat $\left(T_{W}-T_{\text {sat }}\right)$ decreases since

$$
\left(T_{W}-T_{\text {sat }}\right)+\left(T_{\text {sat }}-T_{B}\right)=\left(T_{W}-T_{B}\right)
$$

This is utilized as a criterion for determining the dominance of natural convection over nucleate boiling.

Depending upon the level of heat flux and subcooling, increasing acceleration at constant heat flux and subcooling can cause the heater surface superheat to increase and/or decrease. Figure 7 shows that for subcooling in the range $0^{\circ} \mathrm{C} \leqslant\left(T_{\text {sat }} \quad T_{B}\right) \leqslant 5^{\circ} \mathrm{C}$, a change in acceleration from $a / g=1$ to $a / g=100$ causes the superheat to increase monotonically approximately $2^{\circ} \mathrm{C}$ for $Q_{T} / A_{T}=129400 \mathrm{~W} / \mathrm{m}^{2}$, while at $Q_{T} / A_{T}=$ $11500 \mathrm{~W} / \mathrm{m}^{2}$ it decreases monotonically approximately $10^{\circ} \mathrm{C}$. In between, the surface superheat increases and then decreases. This behavior is evidence of the relative contributions of nucleate boiling and natural convection to the total heat transfer rate. It was found in 
Figs. 4 and 6 above, that the active site density and maximum bubble size decrease markedly with increasing acceleration, and it might be concluded that the contributions of the bubbles to the heat transfer is diminished by incrcasing acceleration. Consequently, increasing acceleration results in an increase in superheat at those heat flux levels for which nucleate boiling predominates, whereas increasing acceleration results in a decrease in superheal at those heal flux levels for which natural convection predominates. Beckman [6] and Graham [5] have observed that increasing acceleration can suppress boiling entirely, and this is suggested here by the curves for $Q_{T} / A_{T}=11500 \mathrm{~W} / \mathrm{m}^{2}$ at $a / g=10$ and $a / g=100$ and the curve for $Q_{T} / A_{T}=21100 \mathrm{~W} / \mathrm{m}^{2}$ at $a / g=100$. These have a constant slope $\mathrm{d}\left(T_{W}-T_{\text {sat }}\right) / \mathrm{d}\left(T_{\text {sat }}-T_{B}\right)=-1$, signifying that $\left(T_{W}-T_{B}\right)$ is constant, the condition required for the dominance of natural convection over nucleate boiling.

\section{Boundary layer thickness}

Figure 8 shows typical results of measurements of fluid temperature distributions adjacent to the heating surface, using a thermocouple of $2.54 \times$ $10^{-2} \mathrm{~mm}$ dia. wire suspended parallel to the surface. The vertical bars at each point represent

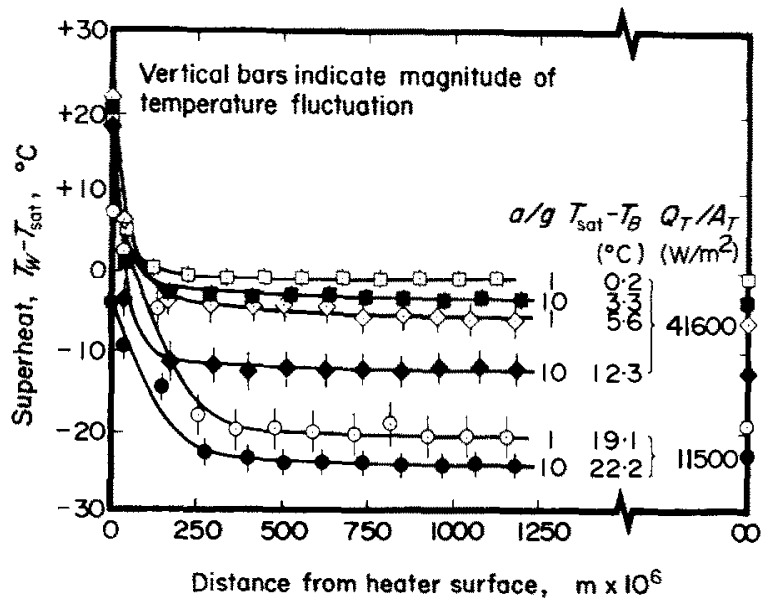

FIg. 8. Temperature profiles. the magnitude of the temperature fluctuations observed about the mean. It can be noted, although more so from the complete set of data, that these fluctuations increase as subcooling increases, for constant heat flux and acceleration. The fluctuations decrease as heat flux increases for constant subcooling and acceleration, and decrease as acceleration increases for constant subcooling and heat flux. Defining the boundary layer thickness as the distance from the heat transfer surface at which the temperature gradient becomes approximately constant, the variation of this quantity with heat flux, subcooling and acceleration is shown in Fig. 9. Increasing the

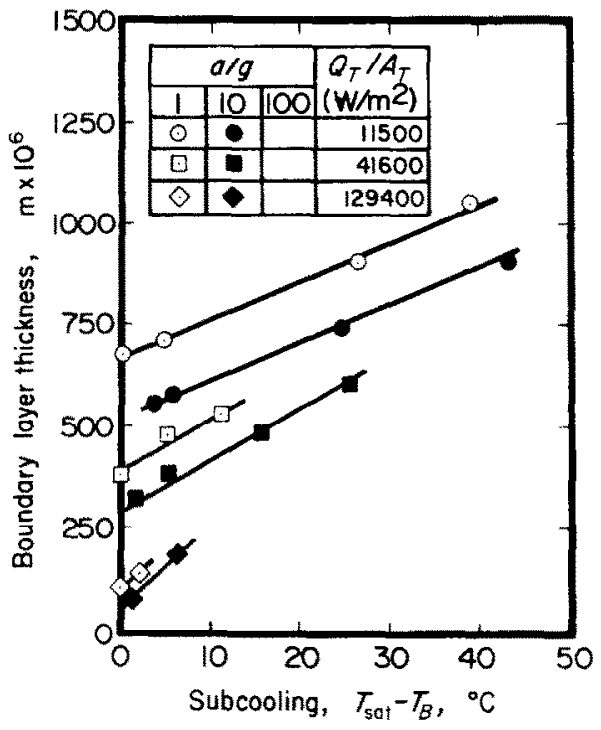

Fig. 9. Boundary layer thickness.

heat flux decreases the boundary layer thickness. which is in accord with the results of Marcus [10] and Lippert [11] for saturated nucleate boiling at standard gravity. On the other hand, increasing subcooling causes the boundary layer thickness to increase. The boundary layer thickness decreases as acceleration increases from $a / g=1$ to $a / g=10$. Although it was not 
possible to measure the boundary layer thickness at $a / g=100$ because of limitations of the probe positioning mechanism, it is believed that the boundary layer thickness would decrease further as acceleration increases from $a / g=10$ to $a / g-$ 100.

\section{DISCUSSION}

In this section, the adequacy of six different models which have been proposed to describe nucleate boiling heat transfer is examined. The extent of agreement between theory and experiment is indicated by a heat flux ratio, defined as the ratio of the predicted heat flux to the measured heat flux. The predicted heat flux is computed by substitution of the independent measurements of surface temperature, boundary layer thickness, average population density, active site density, frequency of bubble emission and maximum bubble size into the appropriate relationships. For the first three models, namely the latent heat transport model, the vapour liquid exchange model and the enthalpy transport model, for which it is reasonable to resolve the boiling phenomenon into natural convection and nucleate boiling components, the heat flux ratio was computed by dividing the nucleate boiling heat flux predicted by the model under investigation by the nucleate boiling heat flux obtained by subtracting the natural convection heat flux from the total heat flux according to

$$
\begin{aligned}
\frac{Q_{N B}}{A_{T}}= & {\left[\frac{Q_{T}}{A_{T}}-\frac{Q_{N C}}{A_{N C}}\left(\frac{A_{N C}}{A_{T}}\right)\right]=\frac{Q_{T}}{A_{T}} } \\
& -110 \cdot 5(a / g)^{\frac{1}{3}}\left(T_{W}-T_{B}\right)^{\frac{4}{3}} \\
& \times\left[1-3 \frac{\pi}{4} D_{\max }^{2}\left(\frac{n}{A_{T}}\right)\right]^{*} .
\end{aligned}
$$

* The coefficient 16.0 which appears in the ratio

$$
\left[\frac{16 \cdot 0(a / g)^{\prime}\left(T_{W}-T_{B}\right)^{\frac{4}{3}}}{Q_{T} / A_{T}}\right]
$$

in [1] was inadvertently overlooked in the conversion of British units to SI units. The correct value is $110 \cdot 5$.
For the last three models, namely the source flow model, the wake flow model and the enhanced natural convection model for which it is not possible to separate natural convection from nuclcate boiling, the heat flux ratio was computed by dividing the total heat flux predicted by the corresponding measured value. Accordingly

$$
\begin{aligned}
& \text { Heat Flux Ratio }=\frac{\left(Q_{N B} / A_{T}\right)_{\text {Predicted }}}{\left(Q_{N B} / A_{T}\right)_{\text {Measured }}} \\
& \text { or } \frac{\left(Q_{T} / A_{T}\right)_{\text {Predicted }}}{\left(Q_{T} / A_{T}\right)_{\text {Measured }}}
\end{aligned}
$$

The values computed have been plotted as functions of heat flux, subcooling and acceleration, the three independent variables of the experimental study, for the purposes of comparison.

\section{Latent heat transport model}

It was originally thought that the rate of heat transfer by nucleate boiling was determined by latent heat transport in which each bubble growing and departing or collapsing at the heater surface removed a bubble volume of latent heat. This explanation of the nucleate boiling heat transfer phenomena had been disregarded when Rallis [12] reintroduced it by reporting an experiment in which it could be shown that latent heat transfer and natural convection together accounted for the total heat flux for saturated water boiling on a horizontal wire. In terms of the time averaged measurements of the present investigation, the latent heat transport model may be expressed by the relationship

$$
\left[\frac{Q_{N B}}{A_{T}}\right]_{P}=\rho_{v} h_{f g} \frac{\pi}{6} D_{\max }{ }^{3}\left(\frac{N}{A_{T}}\right) f
$$

which assumes that the vapour bubbles are spherical in shape. Figure 10 depicts the heat flux ratio $\left[Q_{N B} / A_{T}\right]_{P} /\left[Q_{N B} / A_{T}\right]_{M}$ as a function of heat flux, subcooling and acceleration and shows that with the possible exception of saturated boiling at $a / g=1$, each bubble is responsible for the transfer of considerably more heat than 


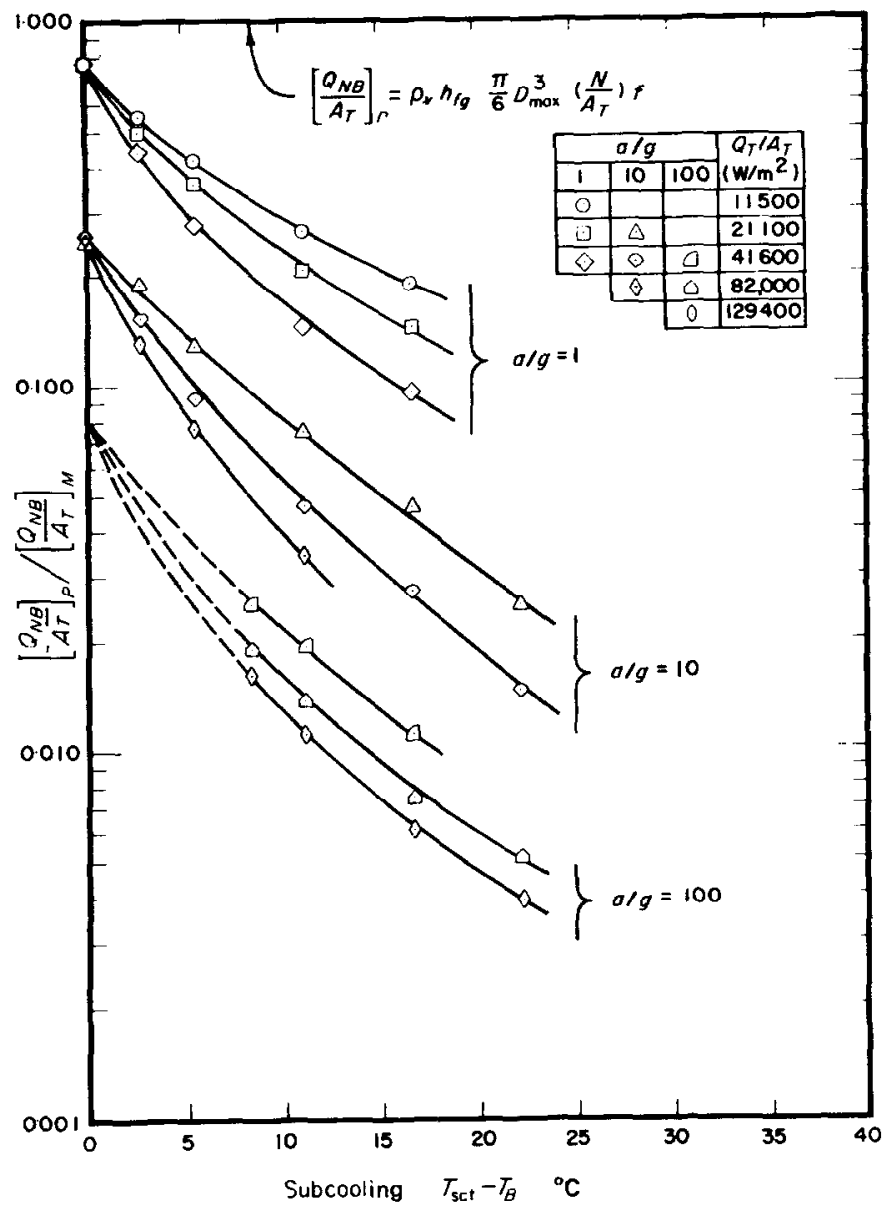

Fig. 10. Latent heat transport model.

predicted by the latent heat transport model, as evidenced by the fact that the curves plotted fall progressively below unity as heat flux, subcooling and acceleration increase. Even accounting for natural convection, more energy is being removed from the heater surface than can be accounted for by latent heat transport. However, it is reasonable to conclude that whatever other mechanisms are in operation, each bubble transports one bubble volume of latent heat away from the heater surface each time that it departs or collapses.

\section{Vapour liquid exchange model}

Forster [13] postulated a vapour liquid exchange mechanism in which heat transfer by nucleate boiling was ascribed to the exchange of a bubble volume of liquid at temperature $T_{W}$ displaced from the heater surface by the growth of the bubble for a bubble volume of liquid at temperature $T_{B}$ which replaces the vapour bubble upon its departure or collapse. This nucleate boiling heat transfer model can be expressed by

$$
\left[\frac{Q_{N B}}{A_{T}}\right]_{P}=\rho_{l} C_{l} \frac{\pi}{6} D_{\max }^{3}\left(T_{W}-T_{B}\right)\left(\frac{N}{A_{T}}\right) f .
$$

Figure 11 illustrates the variation of the heat flux ratio $\left[Q_{N B} / A_{T}\right]_{P} /\left[Q_{N B} / A_{T}\right]_{M}$ with heat flux, subcooling and acceleration and shows that the 


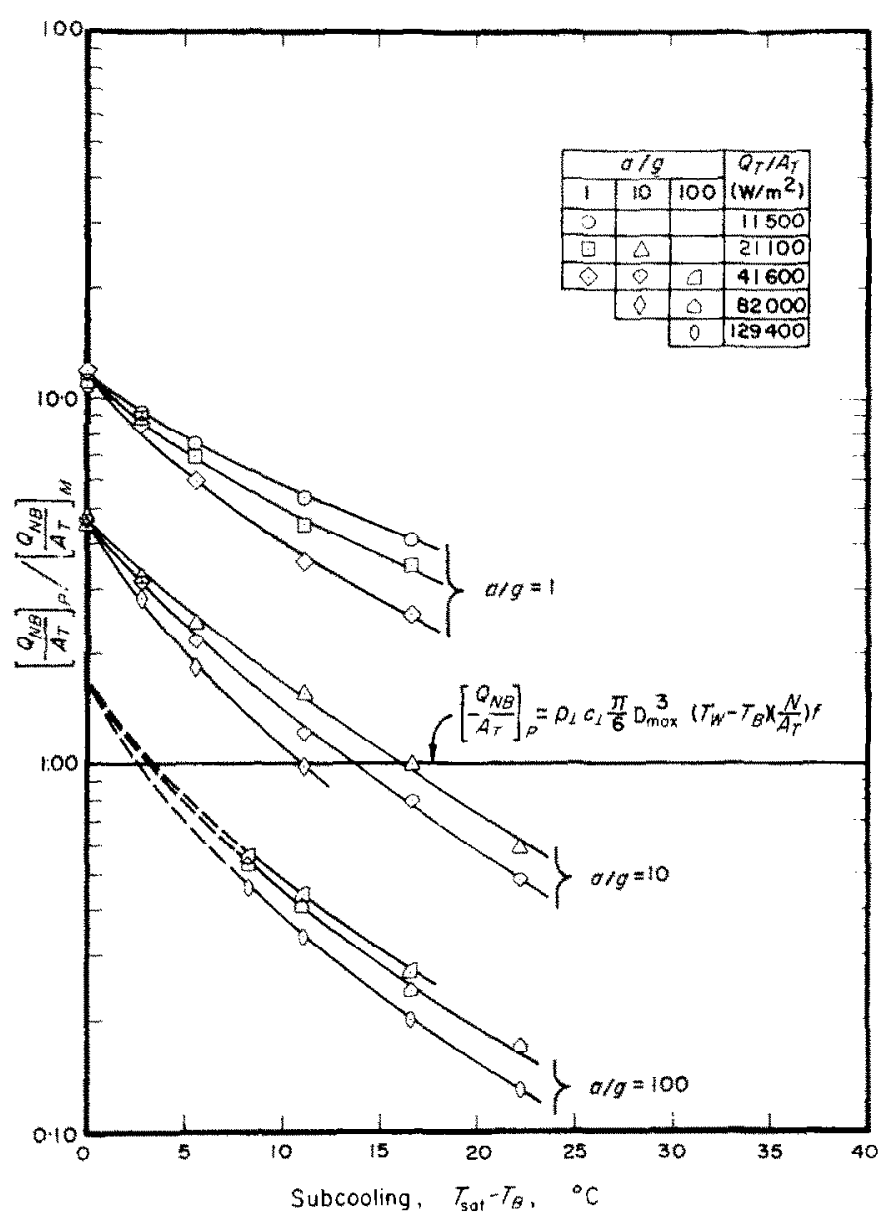

Fig. 11. Vapour liquid exchange model.

vapour liquid exchange model largely overpredicts in as much as the heat flux ratio exceeds unity for all the results at $a / g=1$ and most of the results at $a / g=10$. This observation is not surprising: at the moment of departure or collapse, the vapour bubble exists in a region of extreme temperature variation so that it is unrealistic to consider that the liquid which the vapour bubble has displaced is uniform at the temperature of the wall. In addition, Forster postulated that although the nucleate boiling heat flux predicted by equation (5) is highly dependent upon the bulk temperature, the influence of bulk temperature upon the maximum bubble size, active site density and frequency of bubble emission counteracted this effect. This hypothesis was intended to explain why nucleate boiling heat flux is largely independent of the bulk temperature for small deviations in bulk temperature from the saturated condition. Figure 11 does not support this hypothesis, since the heat flux ratio can be seen to decrease continuously with increasing subcooling.

\section{Enthalpy transport model}

Han [14] formulated a model in which the enthalpy transported by a single bubble was equated to the energy content of the thermal 
boundary layer within the region of influence about each nucleation site, an approximately cylindrical volume twice the bubble departure diameter and equal to the thermal boundary layer thickness in height at the instant of departure. The nucleate boiling heat flux predicted by this relatively sophisticated model is expressed by the relationship

$$
\begin{gathered}
{\left[\frac{Q_{N B}}{A_{T}}\right]_{P}=2 \rho_{l} C_{l}\left[D_{\max }^{2} \delta-\frac{1}{12} D_{\max }^{2}\left(\delta-\delta^{\prime}\right)\right]} \\
\left(T_{W}-T_{B}\right)\left(\frac{N}{A_{T}}\right) f
\end{gathered}
$$

where $\delta=\sqrt{ }\left[\pi \alpha_{l}\left(\tau_{a}+\tau_{i}\right)\right]$ and $\delta^{\prime}=\sqrt{ }^{\prime}\left(\pi \alpha_{l} \tau_{i}\right)$.
Figure 12 depicts the variation of the heat flux ratio $\left[Q_{N B} / A_{T}\right]_{P} /\left[Q_{N B} / A_{T}\right]_{M}$ with heat flux, subcooling and acceleration, and shows that similar to the vapour liquid exchange mechanism. the enthalpy transport model overpredicts at $a / g=1$ and $a / g=10$ although not to the same extent. The influence of heat flux, subcooling and acceleration are such that increasing heat flux, subcooling and acceleration cause a decrease in the heat flux ratio, in common with the other models discussed above.

Source flow model

The source flow model proposed by Bank off [15] ascribes the high rate of heat transfer from a

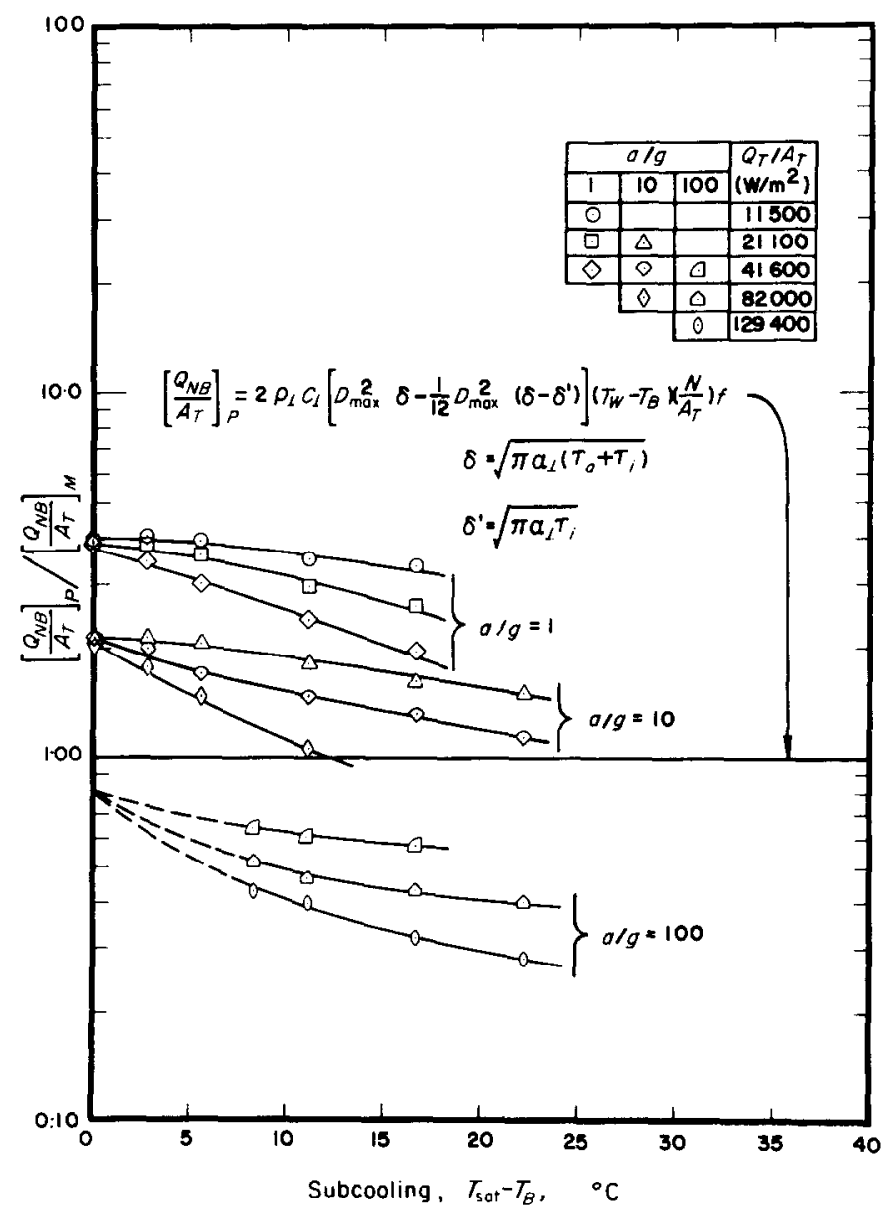

Fig. 12. Enthalpy transport model. 


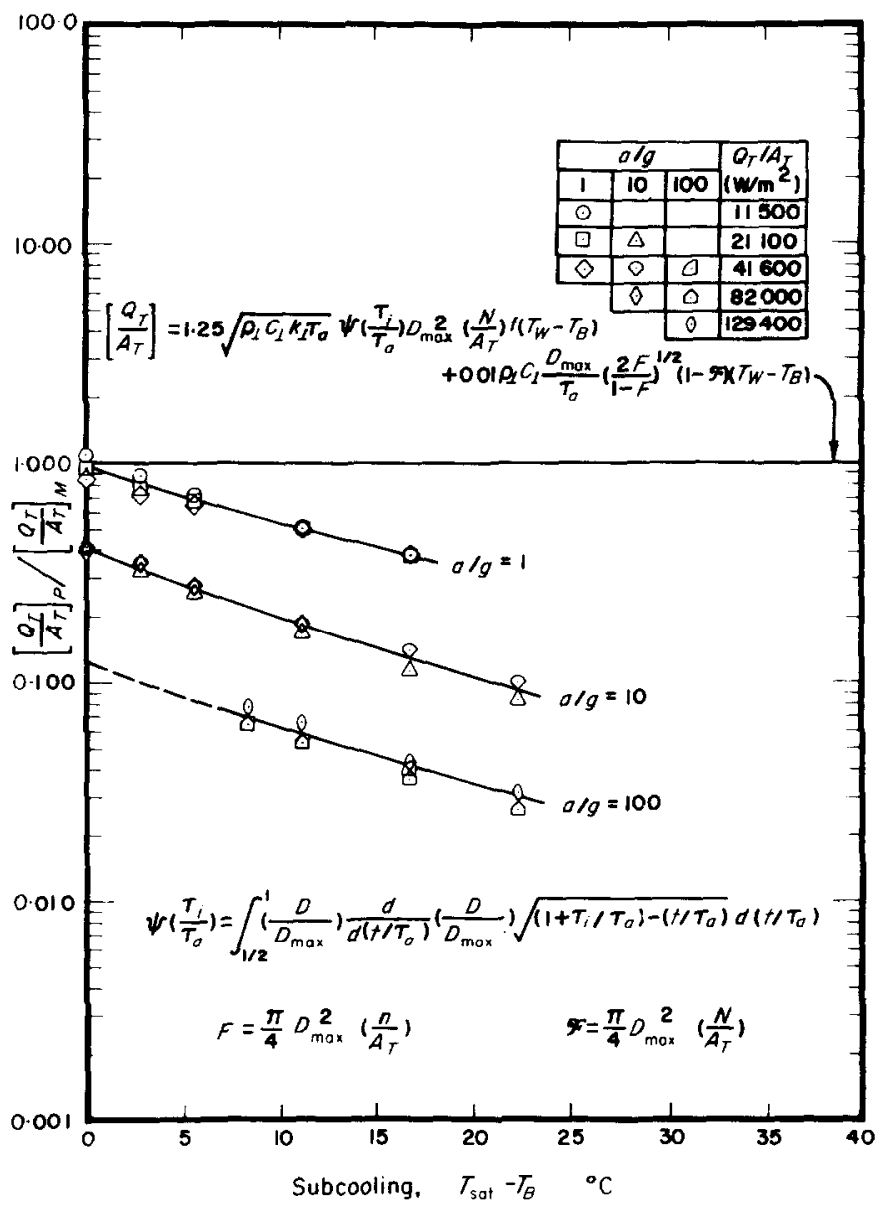

FIG. 13. Source flow model.

boiling surface to the combined action of convection at the surface due to microcurrents induced by the growth and collapse of bubbles at the active nucleation sites (bubble agitation) and transient conduction to the liquid flowing in to replace the vapour bubbles (surface quenching).* This model is conceptually identical to that proposed by Rohsenow [16].

* Bankoff actually proposed a sequential model in which heat was transferred from the heater surface to a two phase layer by bubble agitation and surface quenching and thence to the bulk liquid by eddy diffusion and convective heat transfer at the interface between the vapour bubbles and the bulk liquid. Only the mechanisms acting at the heater surface are considered in this analysis.
Bankoff was able to express this model mathematically without resorting to dimensional analysis by the relationship

$$
\begin{aligned}
{\left[\frac{Q_{T}}{A_{T}}\right]_{P}=} & 1 \cdot 25 \sqrt{ }\left(\rho_{l} C_{l} k_{l} \tau_{a}\right) \psi\left(\frac{\tau_{i}}{\tau_{a}}\right) D_{\max }^{2}\left(\frac{N}{A_{T}}\right) f \\
& \times\left(T_{W^{\prime}}-T_{B}\right)+\text { constant } \rho_{l} C_{l} \\
& \times \frac{D_{\max }}{\tau_{a}}\left(\frac{2 F}{1-F}\right)^{\frac{1}{2}}(1-\mathscr{F})\left(T_{W}-T_{B}\right)(7)
\end{aligned}
$$

involving one arbitrary constant. The first term, which predicts the surface quenching portion of the total heat flux, contains a function of the ratio of active period to inactive period 


$$
\begin{aligned}
\psi\left(\frac{\tau_{i}}{\tau_{a}}\right)= & \int_{\frac{1}{2}}^{1}\left(\frac{D}{D_{\mathrm{max}}}\right) \frac{\mathrm{d}}{\mathrm{d}\left(t / \tau_{a}\right)}\left(\frac{D}{D_{\mathrm{max}}}\right) \\
& \times \sqrt{\left[\left(1+\frac{\tau_{i}}{\tau_{a}}\right)-\left(\frac{t}{\tau_{a}}\right)\right] \mathrm{d}\left(\frac{t}{\tau_{a}}\right)}
\end{aligned}
$$

which relates the heat transfer to the liquid contacting the surface exposed as the bubble collapses to the manner in which the vapour liquid interface recedes. The second term, which predicts the bubble agitation portion of the total heat flux, contains an arbitrary constant which must be obtained from experimental data. In this term, $F$ is the fraction of the surface area instantaneously covered by bubbles given by $\pi / 4\left(D_{\max }{ }^{2}\right)\left(n / A_{T}\right)$ and $\mathscr{F}$ is the fraction of the surface area periodically covered by bubbles given by $\pi / 4\left(D_{\max }{ }^{2}\right)\left(N / A_{T}\right)$. Figure 13 shows that 0.01 is the value of the constant required in the present situation in order to reduce the heat flux ratio $\left[Q_{T} / A_{T}\right]_{P} /\left[Q_{T} / A_{T}\right]_{M}$ to unity for saturated boiling at $a / g=1$. It is significant that this particular treatment of the data correctly accounts for variations in heat flux, although it is apparent that the effects of subcooling and acceleration are not correctly incorporated.

\section{Wake flow model}

Tien [17] advanced a model for nucleate boiling heat transfer based upon the hypothesis that the column of bubbles rising from each nucleation site induced a steady upward flow of the surrounding liquid in its wake which approximated inverted stagnation flow. The mathematical formulation, which involved the use of a heat transfer relationship for inverted stagnation flow, resulted in an expression of the form

$$
\left[\frac{Q_{T}}{A_{T}}\right]_{P}=1.32 \sqrt{(\gamma)} \operatorname{Pr}^{\frac{1}{3}} k_{l}\left(T_{W}-T_{\text {sat }}\right)\left(\frac{N}{A_{T}}\right)^{\frac{1}{2}}
$$

in which $\gamma$ is a parameter relating the heat transfer to the "strength" of the inverted stagnation flow. Tien determined that $\gamma=2150$ for water by comparing experimental results for the thickness of the thermal boundary layer in saturated nucleate boiling water with the relationship

$$
\xi=2 \cdot 44 /\left[\sqrt{ }(\gamma) \operatorname{Pr}^{\frac{1}{3}}\left(\frac{N}{A_{T}}\right)^{\frac{1}{2}}\right]
$$

which predicts the thickness of the thermal boundary layer in stagnation flow. Figure 14 is a plot of boundary layer thickness versus active site density which indicates that boundary layer thickness for the present investigation is similarly inversely proportional to the one half power of active site density for saturated boiling conditions at both $a / g=1$ and $a / g=10$. However for $16.7^{\circ} \mathrm{C}$ subcooling, the boundary layer thickness is inversely proportional to the one eighth power of active site density. Because equation (10) is satisfied for saturated boiling conditions only, Tien's wake flow model cannot be expected to hold for subcooled boiling conditions. Taking

$$
2 \cdot 44 / \sqrt{ }(\gamma) \operatorname{Pr}^{\frac{1}{3}}=765 \times 10^{-3}(a / g)^{-\frac{1}{3}}
$$

then

$$
\sqrt{(y)} \operatorname{Pr}^{\frac{3}{3}}=3 \cdot 18(a / g)^{3}
$$

Consequently

$$
\begin{aligned}
{\left[\frac{Q_{T}}{A_{T}}\right]_{P} } & =1.32 \times 3.18 k_{l}(a / g)^{\frac{1}{3}}\left(T_{W}-T_{\text {sat }}\right)\left(\frac{N}{A_{T}}\right)^{\frac{1}{2}} \\
& =4.20 k_{l}(a / g)^{\frac{1}{t}}\left(T_{W}-T_{\text {sat }}\right)\left(\frac{N}{A_{T}}\right)^{\frac{1}{2}}
\end{aligned}
$$

for saturated nucleate boiling Freon 113.

The variation of $\left[Q_{T} / A_{T}\right]_{P} /\left[Q_{T} / A_{T}\right]_{M}$ with heat flux, subcooling and acceleration depicted in Fig. 15a shows that Tien's wake flow model underpredicts for all values of heat flux, subcooling and acceleration. Boehm [18] suggested that Tien's wake flow model should be modified by the inclusion of an additional term to account for the heat transfer associated with the transient wake flow induced by each bubble departing from the heating surface. Boehm then postulated that the fluid heated by transient conduction during the inactive period was en- 


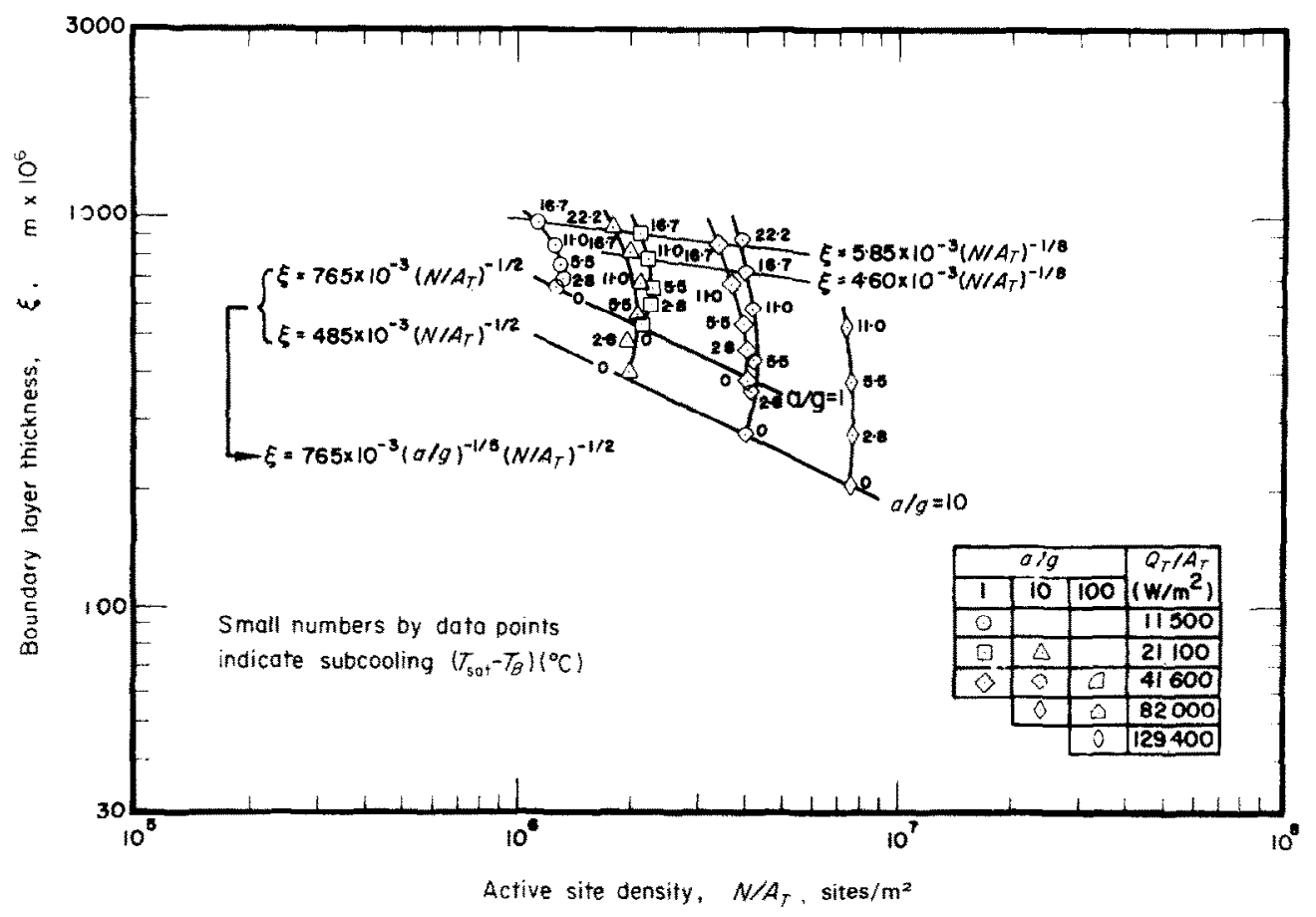

Fig. 14. Boundary layer thickness correlation.

trained in the wake of the preceding bubble, thereby contributing to the inverted stagnation flow at each nucleation site. The combination of these two mechanisms leads to an expression of the form

$$
\begin{aligned}
& {\left[\frac{Q_{T}}{A_{T}}\right]_{P}=4 \cdot 20 k_{l}\left(\frac{a}{g}\right)^{\frac{1}{3}}\left(T_{W}-T_{\text {sal }}\right)\left(\frac{N}{A_{T}}\right)^{\frac{1}{2}}+2 k_{l}} \\
& \times \frac{\left[\left(N / A_{T}\right) /\left(n / A_{T}\right)-1\right]\left(A_{N B} / A_{T}\right)\left(T_{W}-T_{\text {sat }}\right)}{\sqrt{\left(\pi \alpha_{l} \tau_{i}\right)}}
\end{aligned}
$$

in which the term $\left[\left(N / A_{T}\right) /\left(n / A_{T}\right)-1\right]$ is the ratio of the nactive nucleation sites to the active nucleation sites and the term $\left(A_{N \mathrm{~N}} / A_{T}\right)$ is the time averaged fraction of the surface area upon which nucleate boiling occurs based upon the projected area of the bubbles at maximum size. Figure $15 \mathrm{~b}$ shows the modified wake flow model predicts correctly for saturated boiling conditions at $a / g=1$ and that this treatment correctly accounts for the heat flux effect at all levels of acceleration although the model progressively underpredicts as subcooling and acceleration increase.

\section{Enhanced natural convection model}

Zuber [19] observed the similarity between nucleate boiling and turbulent natural convection with respect to the "up draught" induced circulation which governs the heat transfer in both cases. This similarity suggested a model in which the bouyancy of the vapour bubbles in the liquid adjacent to the heater surface augmented the thermally induced bouyancy of the liquid, thereby enhancing the convective heat transfer process, much as turbulent eddies enhance the laminar convective process. The equation predicting turbulent natural convection heat transfer was modified accordingly resulting in the expression 


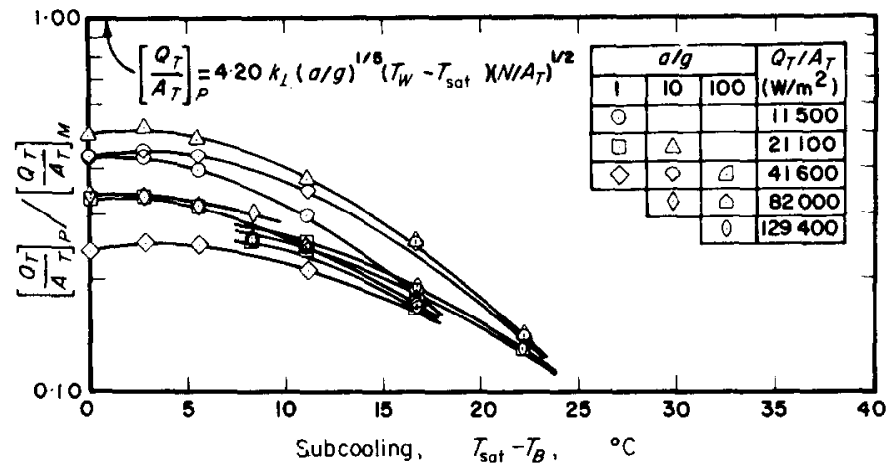

Fig. 15a. Tien wake flow model.

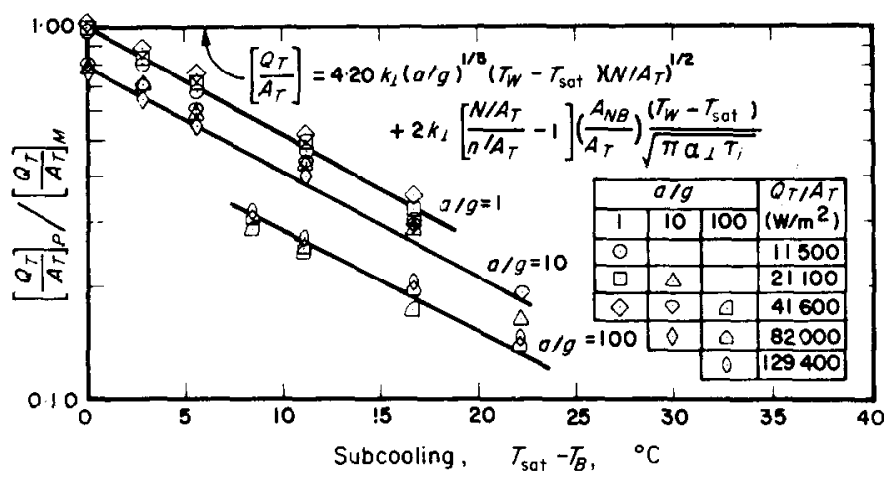

FIG. 15b. Modified wake flow model.

$$
\begin{aligned}
{\left[\frac{Q_{T}}{A_{T}}\right]_{P} } & =0.16\left\{( \frac { a } { g } ) \frac { g \rho _ { l } C _ { l } k _ { I } ^ { 2 } } { v _ { l } } \left[\beta\left(T_{W}-T_{B}\right)\right.\right. \\
& \left.\left.+\varepsilon_{W} \frac{\rho_{l W}-\rho_{v}}{\rho_{l}}\right]\right\}^{\frac{1}{3}}\left(T_{W}-T_{B}\right)
\end{aligned}
$$

in which the volumctric vapour fraction at the wall $\varepsilon_{W}$ is the ratio of the velocity of the vapour flowing away from the heater surface $\pi / 6 D_{\max }^{2}$ $\left(N / A_{T}\right) f$ to the terminal velocity of a single bubble rising in an infinite fluid $U$ given by

$$
1 \cdot 18\left[\left(\frac{a}{g}\right) \frac{\sigma g g_{c}\left(\rho_{l}-\rho_{v}\right)}{\rho_{l}^{2}}\right]^{\frac{1}{t}}
$$

In equation (15), the coefficient $0 \cdot 16$ was substituted for the coefficient 0.32 used by Zuber. In this way, equation (15) reduces to the customarily accepted relationship for turbulent natural convection identically when the volumetric vapour fraction approaches zero, thereby automatically correlating all of the results of the present investigation for which natural convection was predominant. Because of the confusion resulting from the overlap of curves, Fig. 16 has been plotted in three parts showing the variation of $\left[Q_{T} / A_{T}\right]_{P} /\left[Q_{T} / A_{T}\right]_{M}$ with heat flux and subcooling at $a / g=1,10$ and 100 respectively. All the curves plotted tend towards unity as subcooling increases as expected since the vapour volume fraction tends toward zero as subcooling increases. However, the influence of heat flux and subcooling is not correctly accounted for in general. Had the coefficient 0.32 been used as proposed by Zuber, the heat flux at high subcooling would have been overpredicted. 


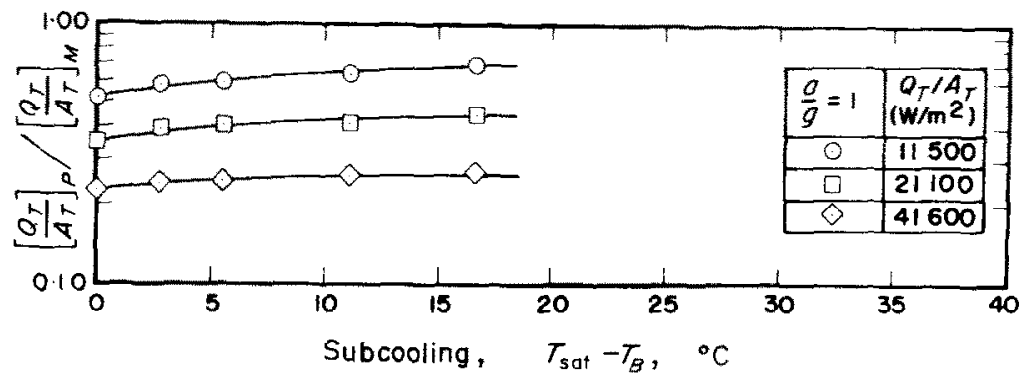

FIG. 16a. Enhanced natural convection model at $a / g=1$.

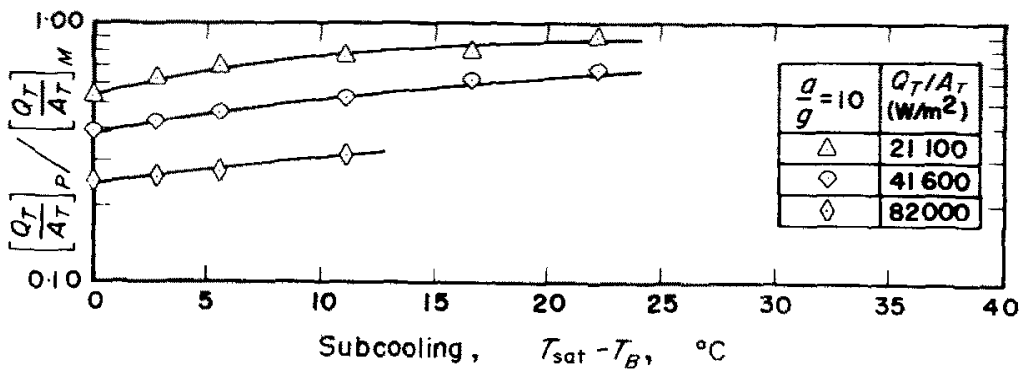

Fic. 16b. Enhanced natural convection model at $a / g=10$.

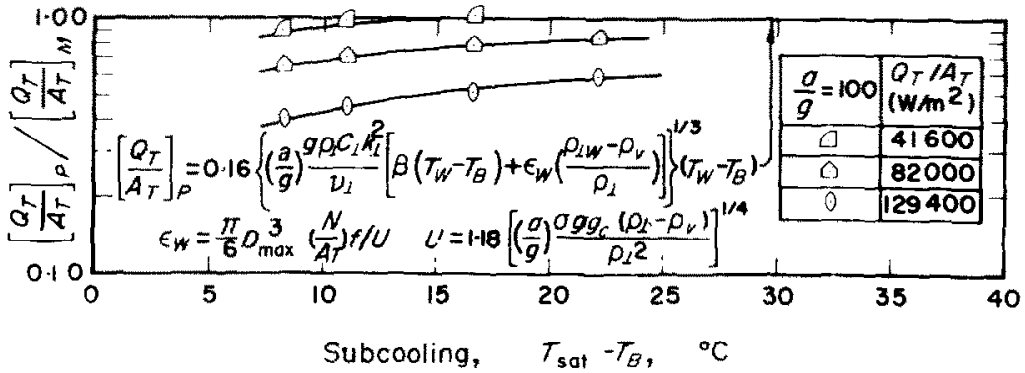

FiG. $16 c$. Enhanced natural convection model at $a / g=100$.

\section{EMPIRICAL CORRELATION}

Körner [20] reported an investigation in which water was boiled on a copper plated nickel heating surface with a fine overlay of nickel on the copper surface at heat fluxes up to $615000 \mathrm{~W} / \mathrm{m}^{2}$, various levels of subcooling from $0^{\circ} \mathrm{C}$ to approximately $40^{\circ} \mathrm{C}$ and acceleration levels ranging from $a / g=50$ to $a / g=1000$. Körner was able to correlate all of his data empirically with an expression of the form

$$
N u=300 R e^{0.667} \operatorname{Pr}^{-0.7}\left(\frac{a}{g}\right)^{-\frac{1}{2}}
$$

in which $N u$ and $R e$ are the bubble Nusselt number and bubble Reynolds number respectively given by

$$
\begin{aligned}
N u=\frac{\left(Q_{T} / A_{T}\right)-\left(Q_{N C} / A_{N C}\right)}{\left(T_{W}-T_{B}\right) k_{i}} & \sqrt{\left(\frac{2 q_{c} \sigma}{g\left(\rho_{l}-\rho_{v}\right)}\right)} \\
& \times \sqrt{\left(\frac{g}{a}\right)}
\end{aligned}
$$


and

$$
\begin{array}{r}
R e=\frac{\left(Q_{T} / A_{T}\right)-\left(Q_{N C} / A_{N C}\right)}{\rho_{l} h_{f g} v_{l}} \frac{T_{W}-T_{\text {sat }}}{T_{W}-T_{B}} \\
\times \sqrt{\left(\frac{2 g_{c} \sigma}{g\left(\rho_{l}-\rho_{v}\right)}\right) /\left(\frac{g}{a}\right) .}
\end{array}
$$

Equation (16) is plotted in Fig. 17 along with the experimental data from the present investigation. The three distinct sets of points indicate that the acceleration effect is not properly accounted for by the term $(a / g)^{-\frac{1}{2}}$.

For those cases in which $Q_{T} / A_{T} \geqslant Q_{N C} / A_{N C}$, the Körner correlation [20] can be rearranged to give

$$
\begin{aligned}
& {\left[\frac{Q_{T} / A_{T}}{\mu_{l} h_{f g}} \sqrt{\left.\left(\frac{g_{c} \sigma}{g\left(\rho_{l}-\rho_{v}\right)}\right)\right]=19 \cdot 2 \times 10^{6} \mathrm{Pr}^{-5 \cdot 1}}\right.} \\
& \quad \times\left[\frac{C_{l}^{3}\left(T_{W}-T_{\mathrm{sat}}\right)^{2}\left(T_{W}-T_{B}\right)}{h_{f g}{ }^{3}}\right]\left(\frac{a}{g}\right)^{-1}
\end{aligned}
$$

Under saturated boiling conditions, the relationship expressed in equation (19) differs only in the body force dependence from the analogous rclationship dcrived from the Rohsenow correlation [16] for saturated nucleate boiling

$$
N u=\text { constant } R e^{0.667} \mathrm{Pr}^{-0.7}
$$

which can be arranged to give

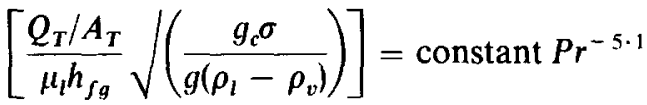

$$
\begin{aligned}
& \times\left[\frac{C_{l}^{3}\left(T_{w}-T_{\mathrm{sat}}\right)^{3}}{h_{f g}{ }^{3}}\right]\left(\frac{a}{g}\right)^{\frac{1}{2}} .
\end{aligned}
$$

In as much as Fig. 17 shows that $N u$ increases with increasing $(a / g)$ at constant $\operatorname{Re}^{0.667} \mathrm{Pr}^{-0.7}$ $(a / g)^{-\frac{1}{2}}$, a relationship with less $(a / g)$ dependence than equation (16) is required to correlate the experimental results.

A more satisfactory correlation of the present data is obtained by changing the exponent of the $(a / g)$ term in equation (16) to obtain the expression

$$
N u=150 \operatorname{Re}^{0.667} \operatorname{Pr}^{-0.7}\left(\frac{a}{g}\right)^{-\frac{1}{6}}
$$

which is plotted in Fig. 18. Equation (22) can be reduced to a form similar to equation (19) to give

$$
\begin{aligned}
& {\left[\frac{Q_{T} / A_{T}}{\mu_{l} h_{f g}} \sqrt{\left.\left(\frac{g_{c} \sigma}{g\left(\rho_{l}-\rho_{v}\right)}\right)\right]=2 \cdot 39 \times 10^{6} \operatorname{Pr}^{-5 \cdot 1}}\right.} \\
& \times\left[\frac{C_{l}^{3}\left(T_{W}-T_{\text {sat }}\right)^{2}\left(T_{W}-T_{B}\right)}{h_{f g}^{3}}\right]
\end{aligned}
$$

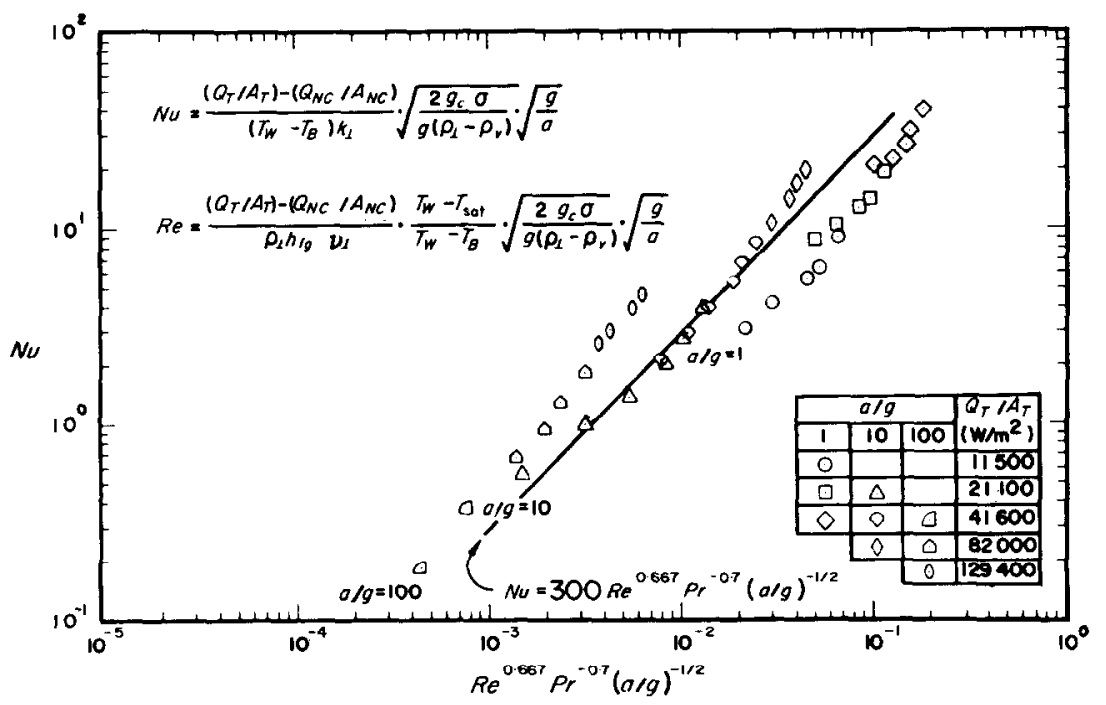

FIG. 17. Körner correlation. 


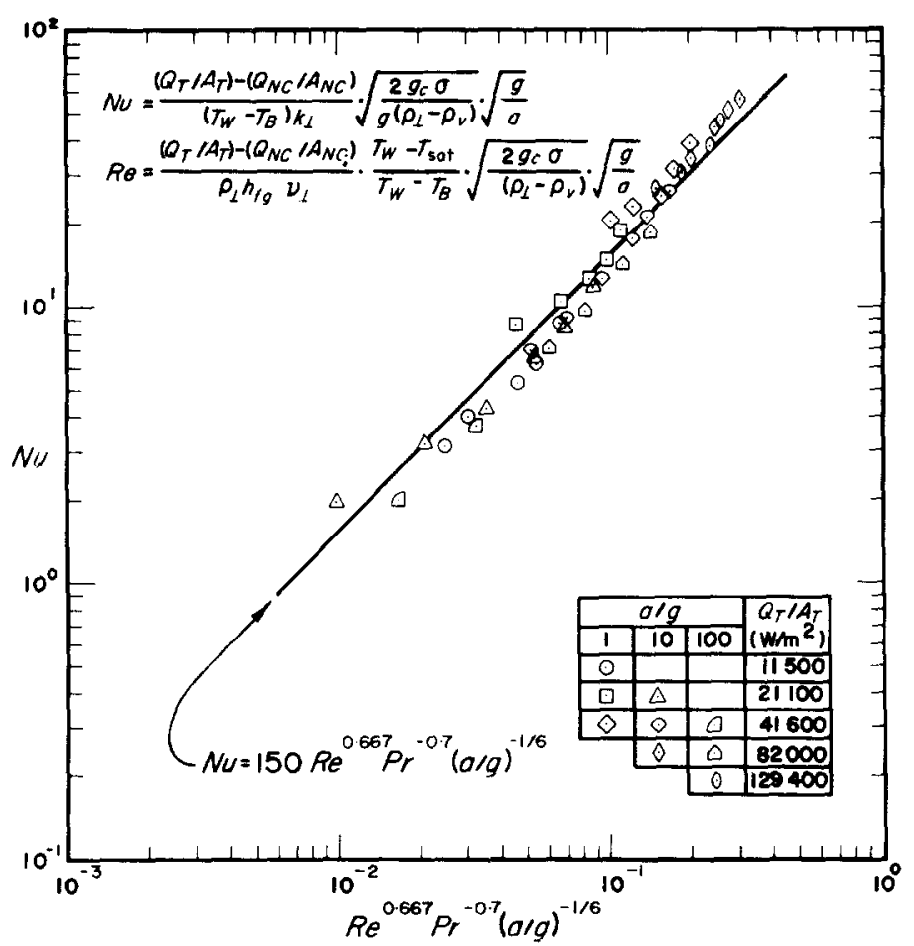

FIG. 18. Empirical correlation.

Although equation (23) appears to suggest that the heat flux becomes independent of the body force for cases in which the natural convection contribution can be neglected, this is not correct since the superheat is still dependent upon the acceleration level. However, within the limits of body forces and heat fluxes thus far covered, it is important to include the contribution of natural convection. To show the role of the body force more explicitly, equation (22) can be written in an alternate form as follows

$$
\begin{gathered}
\left(\frac{Q_{T}}{A_{T}}\right)=0.16 \operatorname{Pr}^{\frac{1}{3}}\left(\frac{g \beta k_{l}^{3}}{v_{l}^{2}}\right)\left[\left(T_{W}-T_{\text {sat }}\right)\right. \\
\left.+\left(T_{\text {sat }}-T_{B}\right)\right]^{\frac{4}{3}}\left(\frac{a}{g}\right)^{\frac{1}{b}}+2 \cdot 39 \times 10^{6} \mathrm{Pr}^{-4 \cdot 1} \\
\times\left\{\frac{k_{l}\left[\left(T_{W}-T_{\text {sat }}\right)+\left(T_{\text {sat }}-T_{B}\right)\right]}{\sqrt{ }\left[g_{c} \sigma / g\left(\rho_{l}-\rho_{v}\right)\right]}\right. \\
\left.\times\left[\frac{C_{l}\left(T_{W} T_{\text {sat }}\right)}{h_{f g}}\right]^{2}\right\}
\end{gathered}
$$

The first term is the contribution of non boiling convection and the second term is the contribution of nucleate boiling. The predicted and measured heat fluxes are compared in Fig. 19.

\section{SUMMARY}

Only the modified wake flow model is capable of predicting boiling heat transfer results for saturated Freon 113 boiling on an oxide coated glass heater surface at standard gravity. All of the models investigated predict decreasing values of the heat flux ratio as subcooling and acceleration increase. Obviously some additional mechanism which is inoperative under saturated boiling conditions but very sensitive to the level of subcooling and acceleration ought to be included in each of the models; mass transfer through the bubbles resulting from the evaporation of a microlayer at the base of the bubble and the subsequent condensation of the vapour 


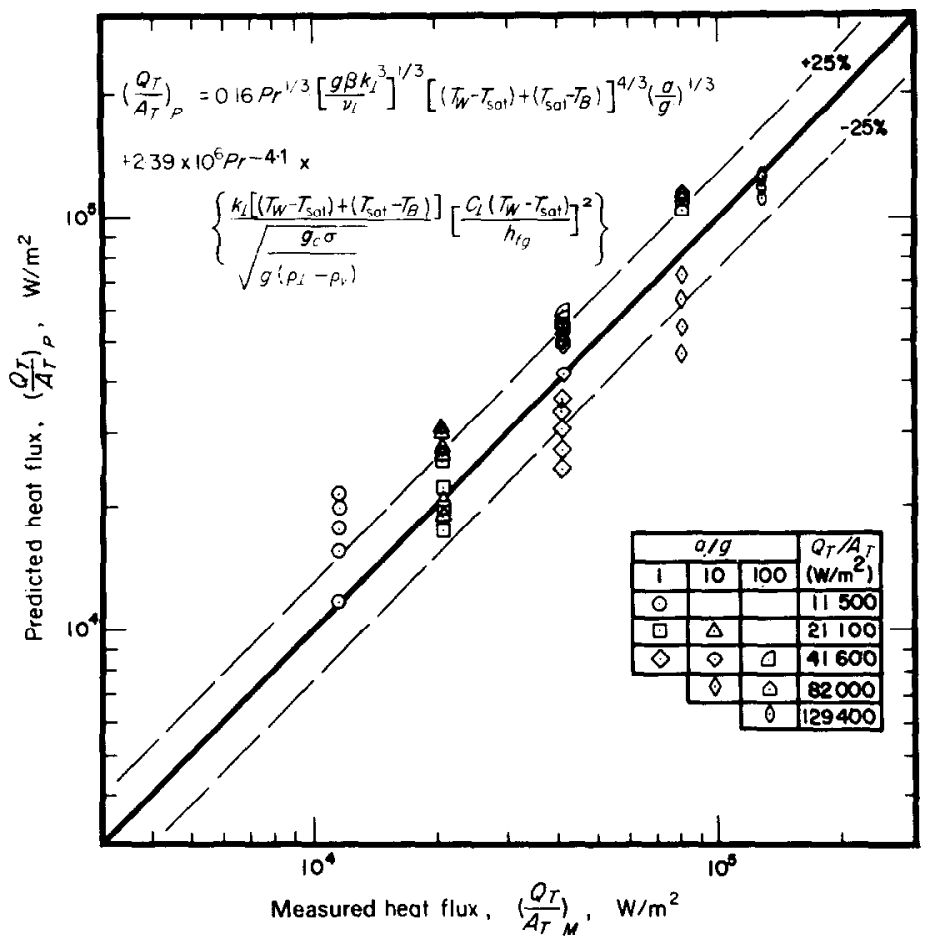

FIG. 19. Comparison of predicted and measured heat fluxes.

at the vapour-liquid interface is a most likely prospect.

A procedure for correlating all of the results of the present investigation was presented.

\section{REFERENCES}

1. R. I. JuDD and H. Merte, JR., Influence of acceleration on subcooled nucleate pool boiling, Proceedings Fourth International Heat Transfer Conference, Versailles/ Paris; 31 August-5 September, 1970.

2. R. L. JUDD, Influence of acceleration on subcooled nucleate boiling, Ph.D. dissertation, University of Michigan, University Microfilms 69-12, 148 (1968).

3. J. W. WestWATER and D. B. KIRBY, Bubble and vapour behaviour on a heated horizontal plate during pool boiling near burnout, Chem. Engng Prog. Symp. Ser. 61, 238-248 (1965)

4. R. F. Gaertner and J. W. Westwater, Population of active sites in nucleate boiling heat transfer, Chem. Engng Prog. Symp. Ser. 56, 39-48 (1960).

5. R. W. Graham and R. C. Hendricks, The study of the effect of multi-G accelerations on nucleate boiling ebullition, NASA TN D-1196 (1963).

6. W. A. Beckman and H. Merte, JR., A photographic study of boiling in an accelerating system, $J$. Heat Transfer 87, 374-380 (1965).
7. S. J. D. Van Stralen, The mechanism of nucleate boiling in pure liquids and binary mixtures, Int. J. Heat Mass Transfer 10, 1485-1498 (1967).

8. R. F. Gaertner, Photographic study of nucleate pool boiling on a horizontal surface, J. Heat Transfer 87 , 17-29 (1965).

9. H. Merte and J. A. Clark, Pool boiling in an accelerating system, J. Heat Transfer 83, 1-10 (1961).

10. B. D. MARcus and D. Dropkin, Measured temperature profiles within the superheated boundary layer above a horizontal surface in saturated nucleate pool boiling of water, J. Heat Transfer 87, 333-341 (1965).

11. T. E. Lippert and R. S. Dougall, A study of temperature profiles measured in the thermal boundary layer of water, Freon 113 and methyl alcohol during pool boiling, $J$. Heat Transfer 90, 1-6 (1968).

12. C. J. RALLIS and H. H. JAWUREK, Latent heat transport in saturated nucleate boiling, Int. J. Heat Mass Transfer 7, $1051-1068$ (1964).

13. H. K. Forster and R. Grief, Heat transfer to a boiling liquid-mechanisms and correlations, J. Heat Transfer 81, 43-53 (1959).

14. C. Y. HAN and P. Griffith, The mechanism of heat transfer in nucleate pool boiling, Int. J. Heat Mass Transfer 8, 887-914, (1965).

15. S. G. BANKoFF, On the mechanism of subcooled nucleate boiling, Chem. Engng Prog. Symp. Ser. 57, 156-172 (1961). 
16. W. H. RoHsenow, A method of correlating heat transfer data from surface boiling liquids, Trans. Am. Soc. Mech. Engrs 74, 969-976 (1952).

17. C. L. TIEN, A hydrodynamic model for nucleate pool boiling, Imt. J. Heat Mass Transfer 5, 533-540 (1962).

18. R. F. BOFHM and J. H. LIFNHARD, Transient effects in Tien's nucleate boiling model, ASME Paper 64-WA/HT* $34,(1964)$.
19. N. ZuBER, Nucleate bolling. The region of isolated bubbles and the similarity with natural convection, Int. J. Heat Mass Transfer 6, 53 . 78 (1963).

20. W. KörNer, Einfluss hoher Beschleunigung auf den Wärmeübergang beim Sieden, Chemie-Ing-Techn. $\mathbf{4 2}$, $409-414(1970)$.

\section{CALCUL DES FLUX THERMIQUES DANS L'ÉBULLITION NUCLEEEE POUR DIFFERENTS NIVEAUX DE SOUS-REFROIDISSEMENT ET D'ACCÉLERATION}

Résumé-Les prédictions de flux thermique de six modèles différents proposés pour expliquer le phénomène d'ébullition nuclée sont comparées avec les mesures de flux thermique correspondant aux mêmes niveaux de sous-refroidissement et d'accélération. On montre qu'aucun de ces modèles ne peut évaluer correctement le flux thermique dans l'ébullition nucléée avec des conditions autres que celles d'ébullition saturée pour une gravité standard et que tous les modèles s'accordent pour prédire les valeurs décroissantes du flux thermique lorsque le sous-refroidissement et l'accélération augmentent. Cette observation suggère l'omission de quelque mécanisme additionnel qui est inopérant sous des conditions d'ébullition saturée pour une gravité standard mais qui est très sensible au niveau de sous-refroidissement et d'accélération.

On présente une procédure empirique pour unifier les résultats utilisés lors des comparaisons.

\section{BERECHNUNGSVERFAHREN ZUR BESTIMMUNG DER WÄRMESTROMDICHTE FÜR DAS BLASENSIEDEN BEI VARIATION VON UNTERKÜHLUNGSGRAD UND BESCHLEUNIGUNG}

Zusammenfassung- Die Wärmestromdichten, berechnet mit sechs verschiedenen zur Klärung des Siedephänomens vorgeschlagenen Modellen, werden mit den entsprechenden Messungen der Wärmestromdichte bei denselben Unterkühlungsgraden und Beschleunigungen verglichen. Es zeigt sich, dass keines dieser Modelle die Wärmestromdichte beim Blasensieden für andere als für die Bedingungen des Blasensiedens bei Sättigung unter Normalbeschleunigung hinreichend wiedergibt und dass alle Modelle darin übereinstimmen, dass sie für zunehmende Unterkühlung und Beschleunigung abnehmende Werte für die Wärmestromdichte liefern. Diese Beobachtung verdeutlicht das Fehlen von einigen zusätzlichen Mechanismen, die zwar für das Blasensieden bei Sättigung unter Normalbeschleunigung unwirksam sind, die sich aber sehr empfindlich auf den Unterkühlungsgrad und die Beschleunigung auswirken. Es wird ein empirisches Verfahren zur Korrelation der Ergebnisse, die für den Vergleich benutzt wurden, vorgestellt.

\section{РАСЧЁТ ТЕПЛОВОГО ПОТОКА ПІРИ ЯДЕРНОМ КИПЕНИИ. ТЕОРЕТИЧЕСКИЕ РАСЧЕТЫ ПРИ ИЗМЕНЕНИИ УРОВНЕЙ НЕДОГРЕВА И УСКОРЕНИЯ}

Аннотация-Проведено сравнение расчета теплового потока для предложенных шести различных моделей ндерного китения с соответствуюпими измерениями теплового потока при тех же значениях недогрева и ускорения. Поназано, что ни одна из данных моделей не даёт возможности удовлетворительно рассчитать тепловой поток при ндерном кипении для всех условий, кроме кипения в условпях насыщения при обычной силе тяжести. Показано также, что при использовании всех әтих моделей значения теплового потока уменынаются при увеличении значений недогрева и ускорения.

Представлена әмпирическая корреляция используемых для сравнения результатов. 